MINI REVIEW

\title{
Estrogens and atherosclerosis
}

J-F Arnal, P Gourdy, R Elhage, B Garmy-Susini, E Delmas, L Brouchet, C Castano, Y Barreira, J C Couloumiers, H Prats, A-C Prats and F Bayard

INSERM U589, Institut L Bugnard, 1 avenue Jean Poulhès, 31403 Toulouse Cédex, France

(Correspondence should be addressed to F Bayard; Email: bayard@toulouse.inserm.fr)

\begin{abstract}
Numerous epidemiological as well as experimental studies have suggested that estradiol $\left(\mathrm{E}_{2}\right)$ prevents atherosclerosis development. However two controlled prospective and randomized studies in women using hormone replacement therapy (HRT) did not confirm this beneficial effect. We then decided to use mouse models of atherosclerosis to define the possible mechanisms involved and the reasons for the discrepancy. We have shown that, although serum cholesterol decreases, this influence on lipid metabolism is negligible. Surprisingly, $\mathrm{E}_{2}$ induces an inflammatory-immune response towards a T helper cell (Th1) profile with increasing interferon- $\gamma$ production that could destabilize atheromatous plaques, and could account for the increase in the frequency of cardiovascular events in women undergoing HRT. At the level of the endothelium, $\mathrm{E}_{2}$ induces an increase in nitric oxide (NO) biodisponibility, but this phenomenon does not concern the development of fatty streaks. Nevertheless, the atheroprotective effect is apparently mediated at the level of the endothelium by a mechanism that has still to be characterized in molecular terms. These new acquisitions constitute a basis for new pharmacological developments allowing the prevention of deleterious effects and preserving the beneficial ones.
\end{abstract}

European Journal of Endocrinology 150 113-117

\section{Introduction}

Numerous epidemiological studies suggest that estrogens protect women against cardiovascular diseases before the age of menopause. After menopause, the cardiovascular risk of women becomes progressively closer to that of men, suggesting an atheroprotective effect of estrogens. However, the two controlled prospective and randomized studies published so far did not demonstrate a beneficial effect of hormone replacement therapy (HRT) whether in secondary prevention, i.e. in women who had already presented a cardiovascular event (Heart and Estrogen/Progestin Replacement Study (HERS) study (1)) or in primary prevention (Women's Health Initiative study (2)). Thus, a better understanding of these non-reproductive effects of estrogens is urgently needed to decide whether or not to treat postmenopausal women who are anxious to prevent bone and vascular pathologies associated with ageing but who also complain of functional manifestations like hot flushes or dyspareunia. Moreover, such studies could provide new information concerning the pathophysiology, diagnosis and treatment of atherosclerosis, and also shed some light on autoimmune diseases, whose appearance and evolution are known to be influenced by estrogen hormones.
Indeed, whereas uncertainties persist concerning the nature and the implications of the effect of estradiol $\left(\mathrm{E}_{2}\right)$ in clinical use, experimental works are much clearer. In experimental models of atherosclerosis, generally studied at the initial stages of the atherosclerotic process, i.e. at the stage of fatty streak constitution in various animal species, $\mathrm{E}_{2}$ treatment (possibly combined with progestin administration) prevents the development of fatty streaks when results are compared with castrated animals given a placebo $(3,4)$.

Our group has been working for several years to describe the vascular effects of $\mathrm{E}_{2}$ and to elucidate some of these mechanisms. We have used mice deficient in apolipoprotein E (apoE-KO) which are hypercholesterolemic (3-4g cholesterol/l) and spontaneously develop fatty streaks at the root of the aorta within a few weeks. Castration is followed by an increase in lesion area and, in castrated mice, $\mathrm{E}_{2}$ prevents the fatty streak deposit but serum $\mathrm{E}_{2}$ concentrations of the order of those encountered during gestation are necessary for maximal protection $(5,6)$. In addition, the atheroprotective effect seems to be mainly the consequence of a direct effect of $E_{2}$ on the cells of the arterial wall. Although $\mathrm{E}_{2}$ treatment induces a decrease in serum cholesterol concentrations, the decrease is too low to explain the hormone protective effect $(4-7)$; 
it is also associated with decreases in both low- and high-density (LDL and HDL) fractions of the circulating lipoproteins.

\section{Estradiol and the inflammatory-immune system}

In recent years, atherosclerosis has come to be recognized as active and inflammatory, rather than simply a passive process of lipid infiltration. The inflammatory-immune system is strongly involved in the development of fatty streaks (8). Despite the obvious role played by inflammation at the different stages of atherosclerosis, classical anti-inflammatory drugs (steroid and non-steroid) have never proved their efficacy in this pathology (aspirin being as efficient at anti-aggregant doses as at anti-inflammatory doses). One of our goals has been to establish, using $\mathrm{E}_{2}$, the specific characteristics of the inflammatory mechanisms involved in atherosclerosis. Indeed, hypercholesterolemic mice also deficient in either monocyte-macrophage (through a deficit of macrophage colony stimulating factor) (9) or in mature B and T lymphocytes (RAG-2 gene deficient) (10) respectively develop ten- and twofold less fatty streaks than control hypercholesterolemic mice. Mice deficient in various cytokines in general demonstrated the aggravating role of pro-inflammatory cytokines (such as interferon $\gamma$ (IFN- $\gamma$ ), interleukins (IL)- $1 \alpha$ and $\beta$, IL-12, IL-18) (11-13) and the protective role of anti-inflammatory cytokines (mainly IL-10) (14) in the development of the atherosclerotic process.

The adhesion of leukocytes to the endothelium is a critical step in the initiation and the development of fatty streaks. Leukocytes first undergo selectin and selectin ligand interaction which allows cell rolling along the endothelial surface. Leukocyte chemokine receptors thereby come into contact with chemokines displayed by the endothelium, leading to activation of integrins. This is necessary for subsequent firm adhesion through adhesion molecules of the immunoglobulins superfamily such as intercellular adhesion molecule (ICAM-1) and vascular cell adhesion molecule (VCAM-1). This process is followed by the leukocyte emigration from the vasculature to the subendothelial space. This initial step in fatty streak constitution could represent a relevant target for estrogen hormones, but experimental and epidemiological studies have until now reported conflicting results. We have investigated the effect of $\mathrm{E}_{2}$ and have demonstrated that P-selectin and ICAM-1 are not involved in the protective effect of estrogens; however it is suggested that VCAM-1 could play a role in this process (15).

We then looked at the influence of $\mathrm{E}_{2}$ on the inflammatory-immune cells constituting the atherosclerotic lesions, especially unstable lesions that are prone to lead to acute incidents such as myocardial infarction (16). In this context, we have demonstrated that, whereas $E_{2}$ prevents the deposit of fatty streaks in ApoE-KO mice, it has no effect in mice deficient both in apoE and RAG-2 gene expression, lacking mature $\mathrm{B}$ and $\mathrm{T}$ lymphocytes (17). One hypothesis resulting from these observations is that lymphocytes, or at least a subpopulation of them, were the mediators of the atheroprotective effect. After crossing apoE-KO mice with mice deficient either in $\mathrm{B}, \mathrm{T}$ cell receptor (TCR) $\alpha \beta^{+} \mathrm{T}$ or $\mathrm{TCR} \gamma \delta^{+} \mathrm{T}$ lymphocytes we looked at the development of fatty streaks. We observed that TCR $\alpha \beta^{+} \mathrm{T}$ lymphocytes play a major role in fatty streak development. However, the protective effect of $\mathrm{E}_{2}$ persisted in all the constructed strains showing that none of the lymphocyte subpopulations specifically mediated the atheroprotective effect of $E_{2}$ (R Elhage et al., unpublished observations). We then evaluated the possibility of an anti-inflammatory cytokine production. Further experiments did not confirm this hypothesis. In collaboration with different groups of immunologists, we have demonstrated that the profile of cytokine secretion of cluster of differentiation 4 $\left(\mathrm{CD}^{+}\right)(18)$ as well as natural killer (NK) T lymphocytes ( $\mathrm{P}$ Gourdy et al., unpublished observations) is altered by $E_{2}$ resulting in an increase in IFN- $\gamma$ production and a decrease in anti-inflammatory cytokine production (IL-4, IL-10 and IL-13). Thus, E $\mathrm{E}_{2}$ directs the inflammatory response towards a Th1 profile (the increasing interferon $\gamma$ production). Similarly, we recently observed an increased production of IL-1, $\alpha$ and $\beta$, and IL-18 by macrophages obtained from $E_{2^{-}}$ treated mice compared with macrophages obtained from castrated mice. From these studies, it appears that the inflammatory-immune system is not the mediator of the atheroprotective effect of $\mathrm{E}_{2}$. According to our current understanding, an increase in proinflammatory cytokine production in response to $\mathrm{E}_{2}$ cannot explain its atheroprotective effect. In contrast, it could destabilize atheromatous plaques, and account for the increase in the frequency of cardiovascular events during the year following the start of $\operatorname{HRT}(1,2)$.

\section{Estrogens and endothelium}

The endothelium is uniquely positioned at the interface between the blood and the vessel wall and plays a crucial role in the physiology of circulation $(19,20)$ by performing multiple functions. It is involved in the regulation of coagulation, leukocyte adhesion in inflammation, transvascular flux of cells, liquids and solutes, vessel tone, and vascular smooth muscle growth. One of the main factors in all these activities is endothelium-derived reducing factor (EDRF), which is nitric oxide (NO) or a related nitrosocompound. Besides regulation of vascular tone and smooth muscle cell proliferation, NO might also play a protective role by inhibiting leukocyte adhesion to the endothelium, monocyte chemotaxis and inflammatory 
reactions induced by cytokines. Indeed, inhibition of NO production during the initial weeks of cholesterol feeding in rabbits accelerates atherogenesis and NO production is decreased in atherosclerotic vessels from both human and animal models. Finally, NO probably protects against the late events of atherosclerosis, such as thrombosis, by inhibiting platelet adhesion and aggregation. Different experimental and clinical studies have suggested that the mechanism by which $\mathrm{E}_{2}$ is active is an increased bioavailability of NO. Such an increase could result from enhanced NO production, because endothelial NO synthase gene expression was reported to be increased by $\mathrm{E}_{2}$ in different animal species $(21,22)$. It could also result from a decreased breakdown of NO, because we found that the production of reactive oxygen species (ROS) by cultured bovine aortic endothelial cells was decreased under estrogen treatment. In a poorly understood balance, ROS interacts with NO to form peroxynitrite, thereby destroying NO and diverting ROS away from its dismutation product, hydrogen peroxide $(23,24)$. Two estrogen receptor (RE) subtypes, encoded by two distinct genes, have been characterized RE $\alpha$ and RE $\beta$; of these, RE $\alpha$ has been shown to be the major mediator of the atheroprotective effects of $\mathrm{E}_{2}$ on lesion size in ApoE-KO mice (25). In agreement with these observations, and in in collaboration with Chambon's group (26), we demonstrated that RE $\alpha$ mediates the effect of $E_{2}$ on the production of NO (27). A different mouse model, targeted for ER $\alpha$ through the insertion of Neo gene in exon 1, had been generated by Korach's group in 1993; to date, this mouse model had been considered as 'deficient' in $\operatorname{ER} \alpha(28,29)$. In this model, we have observed the persistence of a truncated form ( 55 versus $66 \mathrm{kD}$ for the wild-type $\mathrm{ER} \alpha$ ) through a peculiar splicing of RE $\alpha$ mRNA. Such an ER $\alpha$ isoform, lacking the $\mathrm{B}$ domain and thus probably the transactivating function of this aminoterminal domain (AF-1), was sufficient to mediate the $\mathrm{E}_{2}$ effect on the endothelial NO production (30). Despite the clear increase in NO biodisponibility under $\mathrm{E}_{2}$ treatment, we have been able to demonstrate that this mechanism was not involved in the protective effect of this treatment against atherosclerosis (31).

Using a series of experimental models, $\mathrm{E}_{2}$ has also been reported to promote endothelial regrowth after endothelial denudation (32), angiogenic activity and endothelial cell migration and proliferation (33). This parameter could also be involved in the phenomenon of atheroprotection. Indeed, the most commonly used therapy of atherosclerotic complications consists of endoluminal angioplasty followed by endovascular stent implantation (34). This procedure consists of impacting the atheromatous plaque in the arterial wall by inflating a balloon. The immediate results are good, but there is deterioration due to a phenomenon of re-stenosis within a few months (in 30-50\% of cases) as a consequence of constrictive remodeling and neo-intimal proliferation of smooth muscle cells. The constrictive remodeling can be prevented by an endovascular stent and this is now implanted almost routinely. In contrast the process leading to the re-stenosis, i.e. neo-intimal proliferation of smooth muscle cells, is not prevented by implantation of a stent and is still responsible for re-stenosis in $20-30 \%$ of cases. To prevent this intrastent re-stenosis, two approaches have been used in the past few years (34). The first approach consists of irradiating the artery endoluminaly. However, irradiation induces radic fibrosis and prevents re-endothelialization, leading to delayed thrombosis. This severe complication led to this therapeutic approach being abandoned. The second approach consists of coating stents with an antimitotic drug (Rapamycine or Taxol) which seems very efficient in preventing neo-intimal hyperplasia. However, this approach inhibits the re-endothelialization, as was demonstrated in large animal models using the balloon technique (35); this could lead, as with radiotherapy, to delayed thrombosis. The best approach, which would consist of favoring re-endothelialization by a functional endothelium with the help of growth factors (such as vascular endothelial growth factor (VEGF) or fibroblast growth factor (FGF)-1 or -2), has failed until now due to the pleiotropic and deleterious effects of these factors.

To evaluate the possible role of $\mathrm{E}_{2}$ in re-endothelialization, we developed a novel model of electric arterial injury in mice; the model consisted of destroying the endothelial and smooth muscle cells in the distal part $(4 \mathrm{~mm})$ of the common carotid artery. This model demonstrated that $\mathrm{E}_{2}$ accelerates the re-endothelialization and that this effect is also mediated by RE $\alpha$ (36). Moreover, the rate of spontaneous re-endothelialization was normal when the production of NO or the activity of VEGF were inhibited but was abolished in FGF-2deficient mice. Indeed, FGF2 was a good candidate to be a partner of $E_{2}$ because $E_{2}$ induces, for example, high levels of Fgf 2 mRNA in the rat ovary (37). However, FGF2 expression is complex since five FGF2 isoforms of $18,22,22.5,24$, and $34 \mathrm{kDa}$ in man and three isoforms of 18,21 and $22 \mathrm{kDa}$ in mouse are synthesized through an alternative use of translation initiation codons (38). These isoforms differ only in their $\mathrm{NH}_{2}$ extremities, which confer a nuclear localization to the high-molecular weight (HMW) CUGinitiated forms, the function of which is largely unknown. In contrast, the smaller AUG-initiated FGF2 $(18 \mathrm{kDa})$ is predominantly cytoplasmic, excreted and stored in the extracellular matrix (39). The AUGinitiated $18 \mathrm{kDa}$ protein is thought to stimulate proliferation and migration and induce the downregulation of the FGF receptors. These are high-affinity transmembrane tyrosine kinase receptors, working in association with low-affinity receptors (heparan-sulfate-containing proteoglycans), activate the mitogen-activated protein (MAP) kinases and/or phospholipase C-dependent pathways. In line with these observations, $\mathrm{E}_{2}$ has 
been reported to stimulate MAP kinase activity via an autocrine loop involving FGF2 (40). Interestingly, the stimulating effect of $E_{2}$ on the rate of spontaneous reendothelialization in mice deficient only in low-molecular weight FGF-2, $18 \mathrm{kDa}$, isoform was normal showing that the HMW forms of FGF-2 are involved in the $E_{2}$ effect. Cultures of endothelial cells obtained from subcutaneous Matrigel plugs allowed demonstration of a direct effect of $\mathrm{E}_{2}$ on FGF-2 gene expression and cell migration, and confirmed an intracrine effect of HMW forms of FGF-2 on this activity (B Garmy Susini et al., unpublished observations). The molecular mechanisms of these interactions are being investigated.

Finally, acceleration of re-endothelialization was followed by a spectacular decrease in fatty streak formation at the site of the carotid wound (L Brouchet et al., unpublished observations). Altogether, this series of data suggests that the site of atheroprotection could be located at the level of the endothelium. Further work is being pursued to confirm this suggestion and determine its molecular mechanisms.

In conclusion, $\mathrm{E}_{2}$ exerts an atheroprotective effect. As summarized in Fig. 1, although serum cholesterol decreases, the influence on lipid metabolism is negligible. Similarly, although $\mathrm{E}_{2}$ induces an increase in endothelial NO biodisponibility, this phenomenon does not concern the development of fatty streaks. Nevertheless, the atheroprotective effect is apparently mediated at the level of the endothelium by a mechanism that has still to be characterized in molecular terms. In contrast, $E_{2}$ also induces an inflammatory-immune

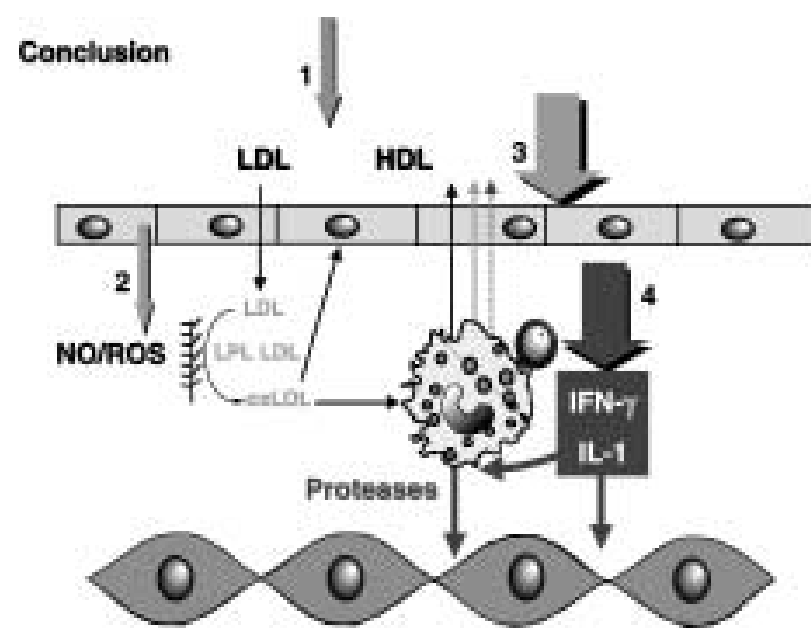

Figure 1 Contrasting effects of $E_{2}$ in atherosclerosis. (1) Serum cholesterol decrease; this influence is negligible in mice.

(2) Increase in endothelial NO biodisponibility; this phenomenon does not play a significant role in preventing the constitution of fatty streaks. (3) The main mechanism of protection is apparently mediated at the level of the endothelium by a mechanism which has still to be characterized in molecular terms. (4) In contrast, $E_{2}$ induces an inflammatory-immune response towards a Th1 profile with increasing interferon $\gamma$ production that could destabilize atheromatous plaques. response towards a Th1 profile with increasing interferon $\gamma$ production that could destabilize atheromatous plaques. This could account for the increase in the frequency of cardiovascular events in women undergoing HRT. These new acquisitions constitute a basis for new pharmacological developments allowing the prevention of deleterious effects and preserving the beneficial ones.

\section{References}

1 Hulley S, Grady D, Bush T, Furberg C, Herrington D \& Riggs B. Randomized trial of estrogen plus progestin for secondary prevention of coronary heart disease in postmenopausal women. Heart and Estrogen/progestin Replacement Study (HERS) Research Group. Journal of the American Medical Association 1998280 605-613.

2 Rossouw JE, Anderson GL, Prentice RL, LaCroix AZ, Kooperberg C, Stefanick ML et al. Risks and benefits of estrogen plus progestin in healthy postmenopausal women: principal results from the Women's Health Initiative randomized controlled trial. Journal of the American Medical Association 2002288 321-333.

3 Arnal JF \& Bayard F. Vasculoprotective effects of oestrogens. Clinical Experimental Pharmacology and Physiology 200128 $1032-1034$.

4 Hodgin JB \& Maeda N. Minireview: estrogen and mouse models of atherosclerosis. Endocrinology 2002143 4495-4501.

5 Bourassa P-A, Milos PM, Gaynor BJ, Breslow JL \& Aiello RJ. Estrogen reduces atherosclerotic lesion development in apolipoprotein E-deficient mice. PNAS 199693 10022-10027.

6 Elhage R, Arnal JF, Pierragi M-T, Duverger N, Fiévet C, Faye J-C et al. Estradiol-17 $\beta$ prevents fatty streak formation in apolipoprotein E-deficient mice. Arteriosclerosis Thrombosis and Vascular Biology 199717 2679-2684.

7 Marsh MM, Walker VR, Curtiss LK \& Banka CL. Protection against atherosclerosis by estrogen is independent of plasma cholesterol levels in LDL receptor-deficient mice. Journal of Lipid Research 199940 893-900.

8 Ross R. Atherosclerosis - an inflammatory disease. New England Journal of Medicine 1999340 115-125.

9 Smith JD, Trogan E, Ginsberg M, Grigaux C, Tian J \& Miyata M. Decreased atherosclerosis in mice deficient in both macrophage colony-stimulating factor (op) and apolipoprotein E. PNAS 1995 $928264-8268$.

10 Dansky HM, Charlton SA, Harper MM \& Smith JD. T and B lymphocytes play a minor role in atherosclerotic plaque formation in the apolipoprotein E-deficient mouse. PNAS 1997 $944642-4646$.

11 Gupta S, Pablo AM, Jiang X, Wang N, Tall AR \& Schindler C. IFN-gamma potentiates atherosclerosis in ApoE knock-out mice. Journal of Clinical Investigation $1997992752-2761$.

12 Mallat Z, Corbaz A, Scoazec A, Graber P, Alouani S, Esposito B et al. Interleukin-18/interleukin-18 binding protein signaling modulates atherosclerotic lesion development and stability. Circulation Research 200189 E41-E45.

13 Lee TS, Yen HC, Pan CC \& Chau LY. The role of interleukin 12 in the development of atherosclerosis in ApoE-deficient mice. Arteriosclerosis Thrombosis and Vascular Biology $1999 \quad 19$ 734-742.

14 Mallat Z, Besnard S, Duriez M, Deleuze V, Emmanuel F, Bureau MF et al. Protective role of interleukin-10 in atherosclerosis. Circulation Research 199985 E17-E24.

15 Gourdy P, Mallat Z, Castano C, Garmy-Susini B, Mac Gregor JL, Tedgui A et al. The atheroprotective effect of 17 beta-estradiol is not altered in P-selectin- or ICAM-1-deficient hypercholesterolemic mice. Atherosclerosis $2003 \mathbf{1 6 6} 41-48$.

16 Virmani R, Kolodgie FD, Burke AP, Farb A \& Schwartz SM. Lessons from sudden coronary death: a comprehensive morphological 
classification scheme for atherosclerotic lesions. Arteriosclerosis Thrombosis and Vascular Biology $2000201262-1275$.

17 Elhage R, Clamens S, Reardon-Alulis C, Getz GS, Fievet C, Maret A et al. Loss of atheroprotective effect of estradiol in immunodeficient mice. Endocrinology $2000141462-465$.

18 Maret A, Coudert JD, Garidou L, Foucras G, Gourdy P, Krust A et al. Estradiol enhances primary antigen-specific CD4 T cell responses and Th1 development in vivo. Essential role of estrogen receptor alpha expression in hematopoietic cells. European Journal of Immunology $200333512-521$.

19 Alexander RW \& Dzau VJ. Vascular biology: the past 50 years. Circulation $2000 \mathbf{1 0 2}$ IV112-116.

20 Libby P \& Simon DI. Inflammation and thrombosis: the clot thickens. Circulation $2001 \mathbf{1 0 3} 1718-1720$.

21 Thompson LP, Pinkas G \& Weiner CP. Chronic 17beta-estradiol replacement increases nitric oxide-mediated vasodilation of guinea pig coronary microcirculation. Circulation $2000 \mathbf{1 0 2}$ 445-451.

22 Goetz RM, Thatte HS, Prabhakar P, Cho MR, Michel T \& Golan DE. Estradiol induces the calcium-dependent translocation of endothelial nitric oxide synthase. PNAS $1999962788-2793$.

23 Arnal JF, Clamens S, Pechet C, Negre-Salvayre A, Allera C, Girolami JP et al. Ethinylestradiol does not enhance the expression of nitric oxide synthase in bovine endothelial cells but increases the release of bioactive nitric oxide by inhibiting superoxide anion production. PNAS 199693 4108-4113.

24 Barbacanne MA, Rami J, Michel JB, Souchard JP, Philippe M, Besombes JP et al. Estradiol increases rat aorta endotheliumderived relaxing factor (EDRF) activity without changes in endothelial NO synthase gene expression: possible role of decreased endothelium-derived superoxide anion production. Cardiovascular Research $199941672-681$.

25 Hodgin JB, Krege JH, Reddick RL, Korach KS, Smithies O \& Maeda N. Estrogen receptor alpha is a major mediator of 17beta-estradiol's atheroprotective effects on lesion size in Apoe-/- mice. Journal of Clinical Investigation 2001107 333-340.

26 Dupont S, Krust A, Gansmuller A, Dierich A, Chambon P \& Mark M. Effect of single and compound knockouts of estrogen receptors alpha (ERalpha) and beta (ERbeta) on mouse reproductive phenotypes. Development 2000127 4277-4291.

27 Darblade B, Pendaries C, Krust A, Dupont S, Fouque MJ, Rami J et al. Estradiol alters nitric oxide production in the mouse aorta through the alpha-, but not beta-, estrogen receptor. Circulation Research $200290413-419$.

28 Lubahn DB, Moyer JS, Golding TS, Couse JF, Korach KS \& Smithies O. Alteration of reproductive function but not prenatal sexual development after insertional disruption of the mouse estrogen receptor gene. PNAS $19939011162-11166$.

29 Couse JF, Curtis SW, Washburn TF, Lindzey J, Golding TS, Lubahn DB et al. Analysis of transcription and estrogen insensitivity in the female mouse after targeted disruption of the estrogen receptor gene. Molecular Endocrinology 19959 $1441-1454$.

30 Pendaries C, Darblade B, Rochaix P, Krust A, Chambon P, Korach KS et al. The AF-1 activation-function of ERalpha may be dispensable to mediate the effect of estradiol on endothelial NO production in mice. PNAS 200299 2205-2210.

31 Elhage R, Bayard F, Richard V, Holvoet P, Duverger N, Fievet C et al. Prevention of fatty streak formation of 17 beta-estradiol is not mediated by the production of nitric oxide in apolipoprotein E-deficient mice. Circulation 199796 3048-3052.

32 Krasinski K, Spyridopoulos I, Asahara T, van der Zee R, Isner JM \& Losordo DW. Estradiol accelerates functional endothelial recovery after arterial injury. Circulation 199795 1768-1772.

33 Morales DE, McGowan KA, Grant DS, Maheshwari S, Bhartiya D, Cid MC et al. Estrogen promotes angiogenic activity in human umbilical vein endothelial cells in vitro and in a murine model. Circulation 199591 755-763.

34 Bennett MR \& O'Sullivan M. Mechanisms of angioplasty and stent restenosis: implications for design of rational therapy. Pharmacology and Therapeutics 200191 149-166.

35 Farb A, Heller PF, Shroff S, Cheng L, Kolodgie FD, Carter AJ et al. Pathological analysis of local delivery of paclitaxel via a polymercoated stent. Circulation $2001 \mathbf{1 0 4} 473-479$.

36 Brouchet L, Krust A, Dupont S, Chambon P, Bayard F \& Arnal JF. Estradiol accelerates reendothelialization in mouse carotid artery through estrogen receptor-alpha but not estrogen receptor-beta. Circulation $2001 \mathbf{1 0 3} 423-428$.

37 Guthridge M, Bertolini J, Cowling J, Runting A \& Hearn MT. Localization of bFGF mRNA in cyclic rat ovary, diethylstilbesterol primed rat ovary, and cultured rat granulosa cells. Growth Factors $1992715-25$.

38 Prats H, Kaghad M, Prats AC, Klagsbrun M, Lelias JM, Liauzun P et al. High molecular mass forms of basic fibroblast growth factor are initiated by alternative CUG codons. PNAS $1989 \mathbf{8 6}$ $1836-1840$

39 Florkiewicz RZ, Anchin J \& Baird A. The inhibition of fibroblast growth factor-2 export by cardenolides implies a novel function for the catalytic subunit of $\mathrm{Na}+, \mathrm{K}+-$ ATPase. Journal of Biological Chemistry 1998273 544-551.

40 Kim-Schulze S, Lowe WL Jr \& Schnaper HW. Estrogen stimulates delayed mitogen-activated protein kinase activity in human endothelial cells via an autocrine loop that involves basic fibroblast growth factor. Circulation 199898 413-421.

Received 21 August 2003

Accepted 17 October 2003 